\title{
The Ditungsten Decacarbonyl Dianion
}

DOI:

10.1039/D0DT01921F

\section{Document Version}

Accepted author manuscript

Link to publication record in Manchester Research Explorer

\section{Citation for published version (APA):}

Ostrowski, J., Atkinson, B., Doyle, L., Wooles, A., Kaltsoyannis, N., \& Liddle, S. (2020). The Ditungsten

Decacarbonyl Dianion. Dalton Transactions, 49(27), 9330-9335. https://doi.org/10.1039/D0DT01921F

\section{Published in:}

Dalton Transactions

\section{Citing this paper}

Please note that where the full-text provided on Manchester Research Explorer is the Author Accepted Manuscript or Proof version this may differ from the final Published version. If citing, it is advised that you check and use the publisher's definitive version.

\section{General rights}

Copyright and moral rights for the publications made accessible in the Research Explorer are retained by the authors and/or other copyright owners and it is a condition of accessing publications that users recognise and abide by the legal requirements associated with these rights.

\section{Takedown policy}

If you believe that this document breaches copyright please refer to the University of Manchester's Takedown Procedures [http://man.ac.uk/04Y6Bo] or contact uml.scholarlycommunications@manchester.ac.uk providing relevant details, so we can investigate your claim.

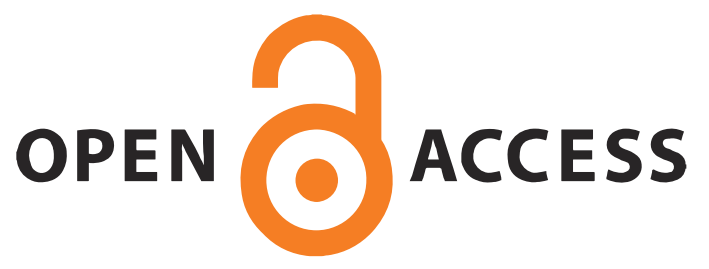




\section{Dalton Transactions}

\section{ARTICLE}

\section{The Ditungsten Decacarbonyl Dianion}

Received 00th January 20xx, Accepted 00th January 20xx

DOI: $10.1039 / x 0 x \times 00000 x$

www.rsc.org/

\author{
Joseph P. A. Ostrowski, ${ }^{\dagger}$ Benjamin E. Atkinson, ${ }^{\dagger}$ Laurence R. Doyle, Ashley J. Wooles, Nikolas \\ Kaltsoyannis, ${ }^{*}$ and Stephen T. Liddle*
}

We report the synthesis and structural authentication of the ditungsten decarbonyl dianion in $\left[(\mathrm{OC})_{5} \mathrm{~W}-\mathrm{W}(\mathrm{CO})_{5}\right][\mathrm{K}(18-$ crown-6)(THF $\left.)_{2}\right]_{2}(\mathbf{1})$, completing the group 6 dianion triad over half a century since the area began. The $\mathrm{W}-\mathrm{W}$ bond is long $[3.2419(8) \AA]$ and, surprisingly, in the solid-state the dianion adopts a $D_{4 \mathrm{~h}}$ eclipsed rather than $D_{4 \mathrm{~d}}$ staggered geometry, the latter of which dominates the structural chemistry of binary homobimetallic carbonyls. Computational studies at levels of theory from DFT to $\operatorname{CCSD}(T)$ confirm that the $D_{4 \mathrm{~d}}$ geometry is energetically preferred in the gas-phase, being $\sim 18 \mathrm{~kJ}^{\mathrm{mol}}{ }^{-1}$ more stable than the $D_{4 h}$ form, since slight destabilisation of the degenerate $W-C O \pi 5 d_{x z}$ and $5 d_{y z}$ orbitals is outweighed by greater stabilisation of the W-W $\sigma$-bond orbital. The gas-phase $D_{4 h}$ structure displays a single imaginary vibrational mode, intrinsic reaction coordinate analysis of which links the $D_{4 \mathrm{~h}}$ isomer directly to the $D_{4 \mathrm{~d}}$ forms, which are produced by rotation around the $\mathrm{W}-\mathrm{W}$ bond by $\pm 45^{\circ}$. It is therefore concluded that the gas-phase transition state becomes a minimum on the potential energy surface when subjected to crystal packing in the solid-state.

\section{Introduction}

Transition metal-carbonyls constitute a class of molecule that has played a pivotal and fundamental role in the advancement of the theory and application of coordination and organometallic chemistries. ${ }^{1}$ Within this family, binary homobimetallic carbonyls with unsupported metal-metal bonds, i.e. being free of stabilising bridging ligands, occupy a key place at the intersection of seminal developments in metal-metal bond and organometallic areas. ${ }^{2}$ The solid-state structures of $\left[(\mathrm{OC})_{5} \mathrm{M}-\mathrm{M}(\mathrm{CO})_{5}\right](\mathrm{M}=\mathrm{Mn}, \mathrm{Tc}, \mathrm{Re}),\left[(\mathrm{OC})_{5} \mathrm{M}-\right.$ $\left.\mathrm{M}(\mathrm{CO})_{5}\right]^{2-}(\mathrm{M}=\mathrm{Cr}, \mathrm{Mo}),\left[(\mathrm{OC})_{4} \mathrm{M}-\mathrm{M}(\mathrm{CO})_{4}\right]^{2-}(\mathrm{M}=\mathrm{Fe}, \mathrm{Ru}, \mathrm{Os})$, and $\left[(\mathrm{OC})_{4} \mathrm{Co}-\mathrm{Co}(\mathrm{CO})_{4}\right]$ have been determined from the $1950 \mathrm{~s}$ onwards. ${ }^{3}$ For $\left[(\mathrm{OC})_{5} \mathrm{M}-\mathrm{M}(\mathrm{CO})_{5}\right]^{n}(n=0,2-)$ complexes the $D_{4 \mathrm{~d}}$ geometry overwhelmingly dominates their solid-state structures, with only one example of $D_{4 \mathrm{~h}}$ symmetry found for $\mathrm{Cr},{ }^{4}$ but the reason for this and any resulting implications were never investigated further and so have remained unknown. ${ }^{5}$ However, studies on the $\mathrm{Mn}$ and Re derivatives have shown that kbar pressures are required to force those complexes to convert from $D_{4 \mathrm{~d}}$ into $D_{4 \mathrm{~h}}$ geometries, ${ }^{6}$ suggesting that the former is lower in energy than the latter. However, considering their fundamental importance, there are remarkably few solidstate structures of homobimetallic carbonyls with unsupported metal-metal bonds. This may reflect difficulties in crystallising them, or that the metal-metal bonds are weak and prone to

\footnotetext{
a. Department of Chemistry, The University of Manchester, Oxford Road, Manchester, M13 9PL, UK.

b.E-mail: steve.liddle@manchester.ac.uk;nikolas.kaltsoyannis@manchester.ac.uk. † These authors contributed equally.

Electronic Supplementary Information (ESI) available: synthetic, spectroscopic, electrochemical, and computational detail. See DOI: 10.1039/x0xx00000x
}

cleavage or require stabilising bridging ligands or coordinated counter ions.

Prominent by its absence from the exemplars above is structural authentication of the free $\left[(\mathrm{OC})_{5} \mathrm{~W}-\mathrm{W}(\mathrm{CO})_{5}\right]^{2-}$ dianion, even though $\left[\mathrm{Na}_{2} \mathrm{~W}_{2}(\mathrm{CO})_{10}\right]$ was first reported in 1963,7 and the $\mathrm{Cr}$ and Mo congeners were structurally characterised in $1970 .{ }^{3 \mathrm{~d}}$ Much more commonly, $\left[\mathrm{W}_{2}(\mathrm{CO}){ }_{10}(\mu-\right.$ $\mathrm{X})$ ] ( $\mathrm{X}=$ formally anionic ligand) moieties are known, and structural authentication of $(\mathrm{OC})_{5} \mathrm{~W}-\mathrm{W}(\mathrm{CO})_{5}$ as an unbridged unit is limited to $\left[\left\{(\mathrm{THF})_{2} \mathrm{Sm}\left(\mathrm{N}_{4} \mathrm{Et}_{8}\right) \mathrm{Sm}(\mathrm{THF})\right\}_{2}\left\{(\mu-\mathrm{CO})_{2} \mathrm{~W}_{2}(\mathrm{CO})_{8}\right\}\right]$ $\left(\mathrm{I}, \mathrm{N}_{4} \mathrm{Et}_{8}=\right.$ meso-octaethylcalix[4]pyrrolide) where the $\mathrm{W}_{2}(\mathrm{CO})_{10}$ unit has $D_{4 \mathrm{~d}}$ symmetry and is stabilised, ${ }^{8}$ and thus influenced, by carbonyl-bound cations as is most likely the case in $\left[\mathrm{Na}_{2} \mathrm{~W}_{2}(\mathrm{CO})_{10}\right]$ itself. ${ }^{7}$ Thus, after almost six decades a structure of free $\left[(\mathrm{OC})_{5} \mathrm{~W}-\mathrm{W}(\mathrm{CO})_{5}\right]^{2-}$ unperturbed by bridging ligands or stabilising counter cations has remained elusive, with the closest relative being homotrimetallic $\left[\mathrm{Na}(\mathrm{DME})_{3}\right]\left[(\mathrm{OC})_{5} \mathrm{~W}\right.$ $\left.\mathrm{W}(\mathrm{CO})_{4}-\mathrm{W}(\mathrm{CO})_{5}\right]$ (II). ${ }^{9}$

Here, as part of our ongoing studies into metal-metal bonding, ${ }^{10}$ we report the synthesis, structural authentication, and characterisation of $\left[(\mathrm{OC})_{5} \mathrm{~W}-\mathrm{W}(\mathrm{CO})_{5}\right][\mathrm{K}(18$-crown6) $\left.(\mathrm{THF})_{2}\right]_{2} \quad$ (1), completing the triad of structurally authenticated free group 6 homobimetallic binary metalcarbonyls. Surprisingly, the free $\left[(\mathrm{OC})_{5} \mathrm{~W}-\mathrm{W}(\mathrm{CO})_{5}\right]^{2-}$ dianion is found to adopt a perfectly $D_{4 \mathrm{~h}}$ eclipsed geometry, instead of the $D_{4 \mathrm{~d}}$ staggered form. Computational analysis reveals that in the gas-phase the $D_{4 \mathrm{~h}}$ isomer is linked directly to the $D_{4 \mathrm{~d}}$ form along the intrinsic reaction coordinate and that the former is a transition state, which leads to the conclusion that crystal packing effects render the $D_{4 \mathrm{~h}}$ form a minimum on the potential energy surface in the solid-state. 


\section{Results and discussion}

\section{Synthetic Considerations}

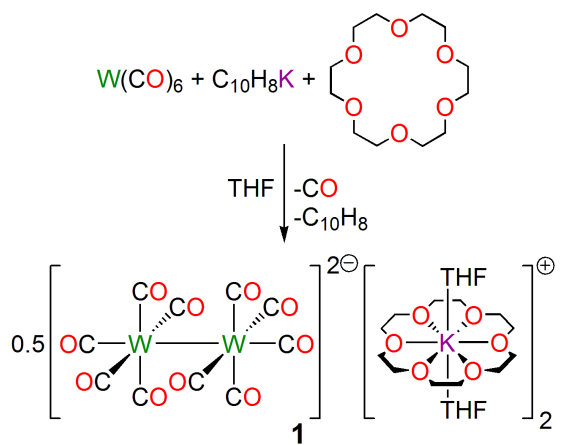

Scheme 1. Synthesis of compound 1 from tungsten hexacarbonyl, potassium naphthalenide, and 18-crown-6 ether precursors.

Dropwise treatment of an equimolar THF solution of tungsten hexacarbonyl and 18-crown-6 ether with a freshly prepared solution of potassium naphthalenide in THF results in immediate formation of a bright red solution. After a three day stir, work-up of the resulting brown solution and recrystallization from THF straightforwardly gave yellow $\left[(\mathrm{OC})_{5} \mathrm{~W}-\mathrm{W}(\mathrm{CO})_{5}\right]\left[\mathrm{K}(18-\text { crown-6)(THF })_{2}\right]_{2}$ (1) in $58 \%$ crystalline yield (Scheme 1). ${ }^{11}$

\section{Crystallographic Analysis}

The solid-state structure of $\mathbf{1}$ (Figure 1a) confirms (i) the unsupported metal-metal bond formulation with one axial and four equatorial carbonyls per tungsten, (ii) the separated ion pair nature, and (iii) that the $\left[(\mathrm{OC})_{5} \mathrm{~W}-\mathrm{W}(\mathrm{CO})_{5}\right]^{2-}$ dianion unit surprisingly adopts an exact $D_{4 \mathrm{~h}}$ rather than $D_{4 \mathrm{~d}}$ geometry, since the centre of the $\mathrm{W}-\mathrm{W}$ bond resides on a crystallographic inversion centre. Point (iii) contrasts to the situation found in $1,{ }^{8}$ and for binary homobimetallic carbonyls generally. The $\mathrm{W}$ W distance in 1 is 3.2421(8) $\AA$, which is significantly longer than the values of 2.74 and 2.79(2) $\AA$ for the sum of the single bond covalent radii of two tungsten atoms ${ }^{12}$ and $\mathbf{I I}, 9$ respectively, but it is closer to the $\mathrm{W}-\mathrm{W}$ bond lengths of $3.1107(6) \AA$ in $\mathrm{I}^{8}$ and $3.2881(1) \AA$ in $\left[\left\{\left(\eta^{5}-\mathrm{C}_{5} \mathrm{Me}_{5}\right) \mathrm{W}(\mathrm{CO})_{3}\right\}_{2}\right] . .^{13}$ The W-C3 distance of 1.906(11) $\AA$ is shorter than the W-C2-5 distances (av. 2.033, range 2.025(11)-2.043(11) $\AA$ ), and the C3O3 distance of 1.201(13) $\AA$ is longer than the other four C-O distances (av. 1.143, range 1.133(13)-1.153(12) Å) suggesting, as anticipated, that there is more $\mathrm{W}-\mathrm{C}$ back-bonding to the two axial carbonyls than the eight equatorial ones. The two [K(18crown-6)(THF) $\left.{ }_{2}\right]^{+}$cations are unremarkable.

\section{Spectroscopic and Electrochemical Analyses}

The ${ }^{1} \mathrm{H}$ NMR spectrum of 1 exhibits the anticipated crown and THF resonances, with no resonances in the range -8 to -12 ppm suggesting the absence of bridging hydrides that would present with ${ }^{183} \mathrm{~W}$ satellites. The ${ }^{13} \mathrm{C}\left\{{ }^{1} \mathrm{H}\right\}$ NMR spectrum is also consistent with the formulation of $\mathbf{1}$, and it exhibits one very weak resonance at $222.86 \mathrm{ppm}$, which is attributed to the equatorial $\mathrm{CO}$ groups, with the two axial $\mathrm{CO}$ groups not being observable due to the poor solubility of $\mathbf{1}$ in THF.

The ATR-IR spectrum of $\mathbf{1}$ (Figure $1 \mathrm{~b}$ ) is characteristic of such a system. Specifically, it features three bands in the carbonyl region centred at $1937\left(\mathrm{~A}_{2 \mathrm{u}}\right), 1863\left(\mathrm{E}_{\mathrm{u}}\right)$, and $1772\left(\mathrm{~A}_{2 \mathrm{u}}\right)$ $\mathrm{cm}^{-1}$. The first band is sharp and weaker compared to the other two that are much broader and intense, which is consistent with $\left[\mathrm{M}(\mathrm{CO})_{5}\right]$ metal-carbonyls with local metal $C_{4 \mathrm{v}}$ symmetry and other examples of $\left[(\mathrm{OC})_{5} \mathrm{M}-\mathrm{M}(\mathrm{CO})_{5}\right]^{\text {n }}$ complexes. ${ }^{7,8,14}$ The Raman spectrum of 1 (Figure $1 \mathrm{~b}$ ) features the anticipated four bands in the carbonyl region at $2019\left(\mathrm{~A}_{1 \mathrm{~g}}\right), 1960\left(\mathrm{~B}_{1 \mathrm{~g}}\right), 1904$ $\left(E_{g}\right)$, and $1794\left(A_{1 g}\right) \mathrm{cm}^{-1}$, whilst a strong absorption at $97 \mathrm{~cm}^{-1}$ $\left(A_{1 g}\right)$ can be assigned to the $W$-W bond stretch, which is lower than the value of $130 \mathrm{~cm}^{-1}$ for $1 .{ }^{7}$ The latter observation is consistent with the respective $\mathrm{W}$-W bond lengths of $\mathbf{1}$ and $\mathbf{I}$, and lower than W-W quadruple bonds that typically are observed at $300 \mathrm{~cm}^{-1} .^{15}$
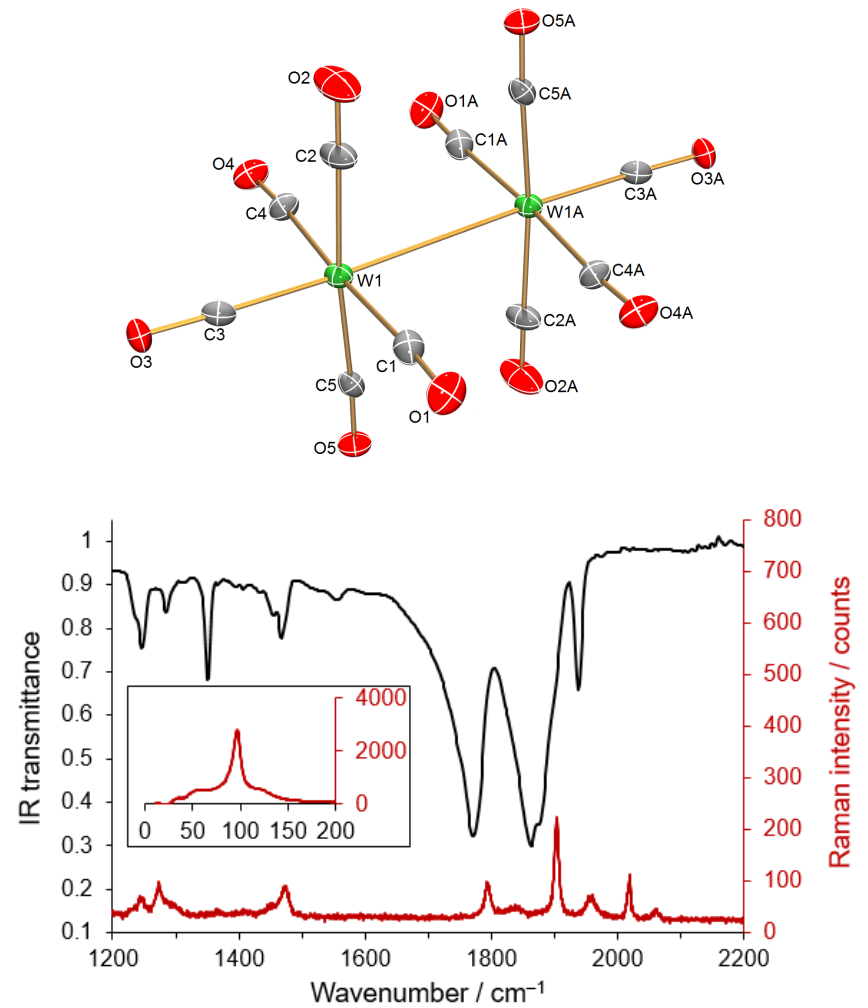

Figure 1. Selected characterisation data for 1. Top: Molecular structure of the dianion component of crystalline $\left[(\mathrm{OC})_{5} \mathrm{~W}-\mathrm{W}(\mathrm{CO})_{5}\right]\left[\mathrm{K}(18 \text {-crown-6)(THF) })_{2}\right]_{2}$ (1) at $150 \mathrm{~K}$ with probability ellipsoids. Selected distances are W1-W1A, 3.2421(8) $\AA$; W1-C1, 2.037(10)

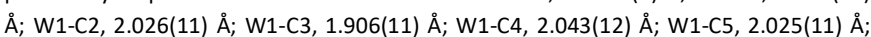

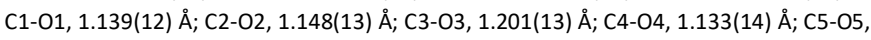
1.153(12) Å. Bottom: Solid-state infrared and Raman spectra of 1 emphasising the carbonyl and metal-metal stretching regions.

The UV/Vis spectrum of 1 exhibits absorptions at 232, 350, and $400 \mathrm{~nm}$, which is similar to isoelectronic [(OC) $)_{5} \mathrm{Mn}$ $\left.\mathrm{Mn}(\mathrm{CO})_{5}\right] .{ }^{16}$ The first is intense and assigned as $\mathrm{d} \rightarrow \pi^{*} \mathrm{MLCT}$, whereas the other two are weak and assigned as $d \rightarrow d$.

The cyclic voltammogram of $\mathbf{1}$ in diethyl ether (Figure S2) reveals two well separated and almost irreversible one- 
electron oxidation events $\left(E_{p, o x}=-0.99\right.$ and $-0.5 \mathrm{~V}$ ) assigned as successive $\mathrm{W}^{0 / 1}$ redox couples. The peak separation of $0.49 \mathrm{~V}$ equates to a hypothetical (noting their mostly irreversible nature) comproportionation constant of $K_{\text {com }}=10^{8.281}$, which would classify $\left[(\mathrm{OC})_{5} \mathrm{~W}-\mathrm{W}(\mathrm{CO})_{5}\right]^{1-}$ as a Robin-Day Class III mixed valence species. Consistent with the irreversible nature of these oxidations, we could not isolate any oxidised species by chemical oxidations, presumably due to their instability. On the basis of computational studies (see below) the electrons removed during these two oxidation events should derive from the W-W bond, which is the computed highest occupied molecular orbital (HOMO) of $\mathbf{1}$. This nicely accounts for the observed oxidatively-induced decomposition and irreversible electrochemical behaviour, and the negative oxidation potentials are consistent with the dianionic nature of the tungsten component of $\mathbf{1}$ and that the $\mathrm{W}-\mathrm{W}$ bond is computed to be diffuse and weak.

\section{Computational Analyses}

To further explore the bonding in the $\left[(\mathrm{OC})_{5} \mathrm{~W}-\mathrm{W}(\mathrm{CO})_{5}\right]^{2-}$ dianion component of $\mathbf{1}$, we turned to computational methods, and performed relaxed energy scans at several levels of theory (Figure 2 and Tables S1 and S2). ${ }^{11}$ In-line with the structural and high pressure literature, at all levels the $D_{4 d}$ geometry is preferred; by $16.7-17.2 \mathrm{~kJ} \mathrm{~mol}^{-1}$ with the B3LYP density functional and $18.4 \mathrm{~kJ} \mathrm{~mol}^{-1}$ using spin-component scaled second-order Møller-Plesset perturbation theory (SCSMP2, where singlet excitations are scaled up by 1.2 , and triplet excitations down by $1 / 3$ ). Coupled-cluster with single, double and perturbative triple excitations $(\operatorname{CCSD}(T))$ single point energy calculations at the SCS-MP2 geometries reinforces the DFT and SCS-MP2 energies, with the $D_{4 \mathrm{~h}}$ geometry being 17.4 $\mathrm{kJ} \mathrm{mol}-1$ higher than the $D_{4 \mathrm{~d}}$ isomer. The $\operatorname{CCSD}(T) T_{1}$ diagnostic is 0.021 in both cases, suggesting that single-reference techniques should suffice. Because, for the dianion, DFT calculations compute positive eigenvalues for some KohnSham orbitals, we performed further calculations with two explicit $\mathrm{Na}^{+}$cations set $4 \AA$ away from each of the axial carbonyls, however these explicit cation calculations give very similar results to those of the dianion. SCS-MP2 provides the best overall match to the crystal structure geometry (optimized variables are given in Tables S3-S5). At each level of theory, the W-W bond length shortens by about $0.1 \AA$ going from $D_{4 \mathrm{~h}}$ to $D_{4 \mathrm{~d}}$ geometry. The introduction of the explicit $\mathrm{Na}^{+}$ cations further reduces the $\mathrm{W}-\mathrm{W}$ bond length by $\sim 0.05 \AA$ for B3LYP calculations, which is consistent with the situation in I where the $\mathrm{Sm}$ ions perform the same stabilising role as $\mathrm{Na}^{+} .{ }^{8}$

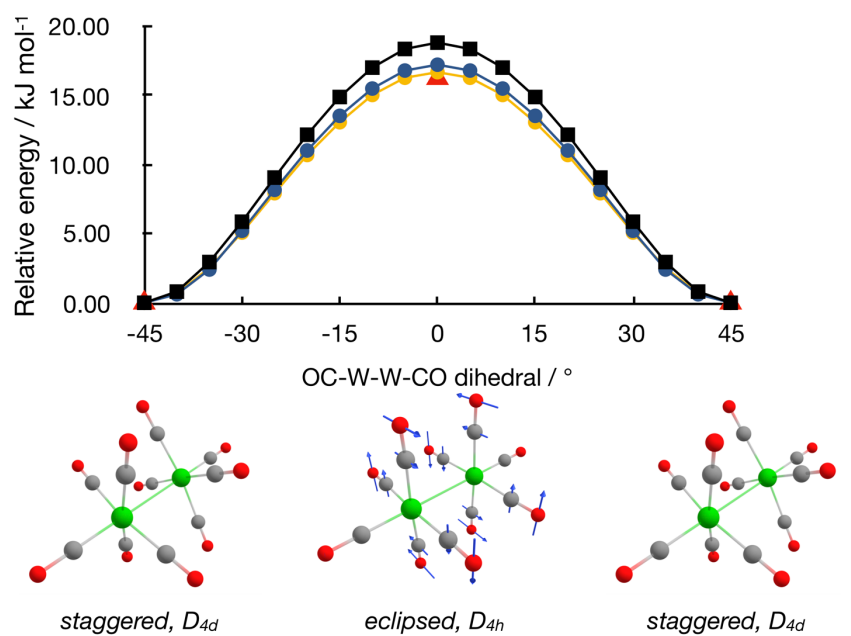

Figure 2. Relaxed energy scans of $\mathbf{1}$, where the geometry is optimised at each point while preserving (at least) $D_{4}$ symmetry and fixing the dihedral angle. Black square: SCSMP2, blue circle: B3LYP with Na cations, yellow circle: B3LYP, red triangle: CCSD(T) at SCS-MP2 optimised geometry. Blue arrows indicate the motion of the twisting imaginary mode at the eclipsed geometry.

The frontier Kohn-Sham orbitals of the B3LYP calculation, with explicit $\mathrm{Na}^{+}$cations, for the $D_{4 h}$ geometry are shown in Figure 3. The $\mathrm{a}_{1 \mathrm{~g}} \mathrm{HOMO}$ is the $\mathrm{W}-\mathrm{W} \sigma$-bond, consistent with the cyclic voltammogram, and the remaining frontier orbitals are $\mathrm{W}$-CO $\pi$-bonding orbitals. a) eclipsed, $D_{4 \mathrm{~h}}$
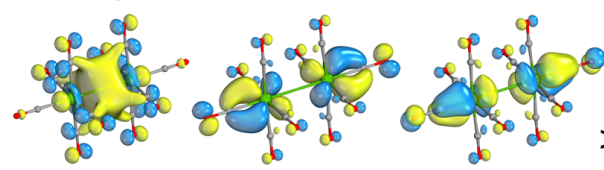

HOMO, $a_{1 g}$

HOMO-1, eg
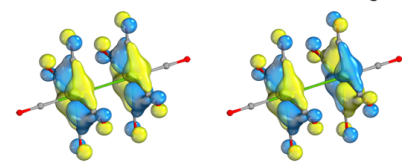

HOMO-2, b2u HOMO-3, b1g

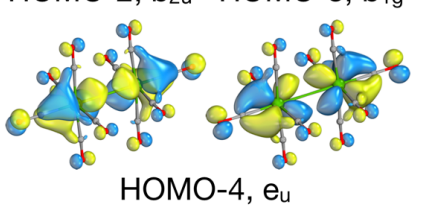

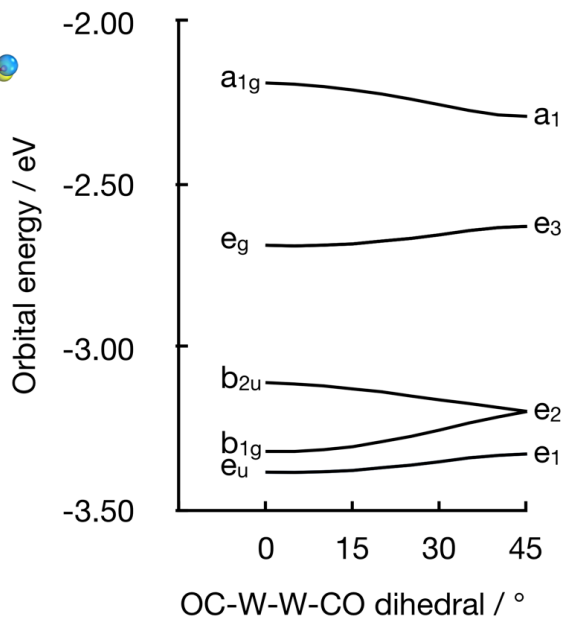

\section{b) staggered, $D_{4 \mathrm{~d}}$}
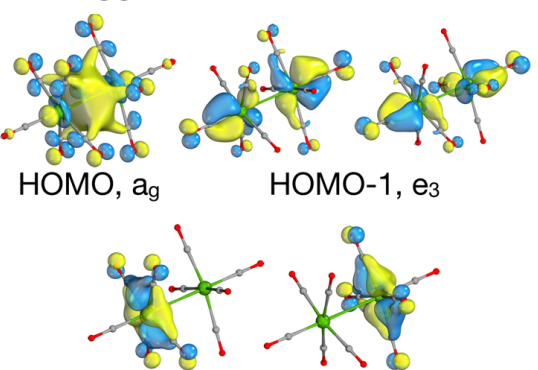

$\mathrm{HOMO}-2, \mathrm{e}_{2}$

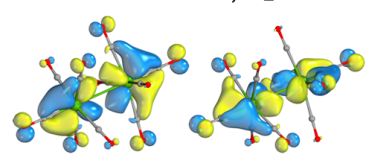

HOMO-3, e

Figure 3. The frontier molecular orbitals of eclipsed (a) and staggered (b) $\left[(\mathrm{OC})_{5} \mathrm{~W}-\mathrm{W}(\mathrm{CO})_{5}\right]^{2-;}$; the W-W $\sigma \mathrm{HOMO}$ and the W-CO $\pi$ bonding orbitals are shown, at the B3LYP level of theory with explicit Na cations. Only one of the doubly degenerate orbitals is shown. The isosurfaces enclose $60 \%$ of the orbital. Green: W, grey: C, red: O. Na omitted for clarity. The energy of these frontier MOs as a function of OC-W-W-CO dihedral angle is plotted (centre). 
Topological analysis of the SCS-MP2 density using the quantum theory of atoms in molecules further supports the orbital-based bonding picture. The ellipticity parameter $\varepsilon$ of the $\mathrm{W}$-W bond critical point (BCP) is zero, as expected given the cylindrical symmetry of the $a_{1 \mathrm{~g}}$ HOMO. Whilst the delocalization index $\delta$ is essentially unchanged from $D_{4 \mathrm{~h}}$ (0.271) to $D_{4 \mathrm{~d}}(0.270)$ geometries, the increase in the BCP electron density $\rho$ ( 0.029 vs $0.033 \mathrm{au})$, and the more negative energy density $H(-0.007$ vs $-0.009 \mathrm{au})$, reflects the increase in covalency due to the shorter bond length, which is consistent with experimental structural and spectroscopic data. The low delocalisation index reflects the weakness of the bond.

To explore the gas-phase preference for the $D_{4 \mathrm{~d}}$ geometry, we analysed the energies of the frontier Kohn-Sham molecular orbitals. Key frontier orbitals, and their energies as a function of the OC-W-W-CO dihedral angle, are shown in Figure 3. Defining the $W$-W bond as the $z$-axis, as the OC-W-W-CO dihedral angle moves from $D_{4 \mathrm{~h}}\left(0^{\circ}\right)$ to $D_{4 \mathrm{~d}}\left(45^{\circ}\right)$ geometry, the W-CO $\pi 5 d_{x y}$ orbitals are largely unaffected; degenerate at $D_{4 d}$ $\left(e_{2}\right)$, with the in- and out-of-phase combinations energetically split for $D_{4 h}\left(b_{2 u}\right.$ and $\left.b_{1 g}\right)$ (Figure 3 ). The four $5 d_{x z}$ and $5 d_{y z}$ orbitals are slightly destabilized from $D_{4 \mathrm{~h}}\left(0^{\circ}\right)$ to $D_{4 \mathrm{~d}}\left(45^{\circ}\right)$, in contrast to the stabilization of the W-W $\sigma$-bond, favouring the $D_{4 \mathrm{~d}}$ geometry. With stabilization of the $\mathrm{W}$-W $\sigma$-bond comes a shorter and stronger $\mathrm{W}-\mathrm{W}$ bond, however the $\mathrm{W}-\mathrm{W} \sigma$-bond remains weak and diffuse, as reflected in the QTAIM analysis, and that the W-W $\sigma$-bond HOMO is only $32.9 \%$ and $33.6 \%$ tungsten-based for $D_{4 \mathrm{~h}}\left(0^{\circ}\right)$ and $D_{4 \mathrm{~d}}\left(45^{\circ}\right)$ respectively.

Frequency analysis of the gas-phase $D_{4 \mathrm{~d}}$ and $D_{4 \mathrm{~h}}$ geometries, using both B3LYP and SCS-MP2, confirms that the $D_{4 \mathrm{~d}}$ geometry is a true minimum structure, with the $D_{4 \mathrm{~h}}$ geometry corresponding to a transition state between two $D_{4 \mathrm{~d}}$ conformations; the imaginary mode of the $D_{4 \mathrm{~h}}$ structure (26.6i $\mathrm{cm}^{-1}$ at SCS-MP2, Figure 2) is characterised by an intrinsic reaction coordinate (IRC) to the two $D_{4 \mathrm{~d}}$ conformations that are $\pm 45^{\circ}$ of it. Notably, the intensities of the carbonyl absorptions match the experimental pattern (Tables S6 and S7), and the computed W-W stretch is $117.5 \mathrm{~cm}^{-1}$ at the $D_{4 \mathrm{~d}}$ geometry vs $100.2 \mathrm{~cm}^{-1}$ when $D_{4 \mathrm{~h}}$ (and $97 \mathrm{~cm}^{-1}$ experimentally), again reflecting the weakened $\mathrm{W}-\mathrm{W}$ bond at the $D_{4 \mathrm{~h}}$ geometry.

The majority of binary homobimetallic carbonyls adopt $D_{4 \mathrm{~d}}$ geometries in crystalline phases. For example, of the five reports of $\left[(\mathrm{OC})_{5} \mathrm{Cr}-\mathrm{Cr}(\mathrm{CO})_{5}\right]^{2-}$ four are $D_{4 \mathrm{~d}}$ whilst the fifth is $D_{4 \mathrm{~h}}$; with two $\left[\mathrm{K}(2,2,2 \text {-cryptand) }]^{+}\right.$cations a $D_{4 \mathrm{~h}}$ geometry is adopted, ${ }^{4}$ however replacing $\mathrm{K}$ with $\mathrm{Na}$ in $\left[(\mathrm{OC})_{5} \mathrm{Cr}\right.$ $\left.\mathrm{Cr}(\mathrm{CO})_{5}\right]\left[\mathrm{Na}(2,2,2 \text {-cryptand) }]_{2}\right.$ results in a $D_{4 \mathrm{~d}}$ geometry, ${ }^{17}$ but until now the reason for this was unknown. Our gas-phase calculations on $\left[(\mathrm{OC})_{5} \mathrm{~W}-\mathrm{W}(\mathrm{CO})_{5}\right]^{2-}$ from DFT to $\mathrm{CCSD}(\mathrm{T})$ levels of theory consistently and decisively give a preference for the $D_{4 \mathrm{~d}}$ geometry over the $D_{4 \mathrm{~h}}$. However, experimentally we isolate $\left[(\mathrm{OC})_{5} \mathrm{~W}-\mathrm{W}(\mathrm{CO})_{5}\right]^{2-}$ in its $D_{4 \mathrm{~h}}$ form. On the basis of our structural and computational data, we conclude that crystal packing is responsible for the adoption of a $D_{4 \mathrm{~h}}$ geometry in $\mathbf{1}$, since the predicted preference for the $D_{4 \mathrm{~d}}$ geometry is at most $20 \mathrm{~kJ} \mathrm{~mol}^{-1}$, and this is certainly in the range of crystal packing forces. This implies that the gas-phase transition state becomes a minimum on the potential energy surface when subject to crystal packing forces. Inspection of the crystal packing diagram of 1 supports this view, Figure 4, since this demonstrates how the $D_{4 \mathrm{~h}}$ geometry of the dianion of 1 packs efficiently with two $\left[\mathrm{K}(18 \mathrm{C} 6)(\mathrm{THF})_{2}\right]^{+}$cations, where each channel of $\left[(\mathrm{OC})_{5} \mathrm{~W}-\mathrm{W}(\mathrm{CO})_{5}\right]^{2-}$ dianions is surrounded by four symmetrically disposed channels of $\left[\mathrm{K}(18 \mathrm{C} 6)(\mathrm{THF})_{2}\right]^{+}$cations when viewed down the plane defined by the crystallographic $a$ axis in between the $b$ and $c$ axes.

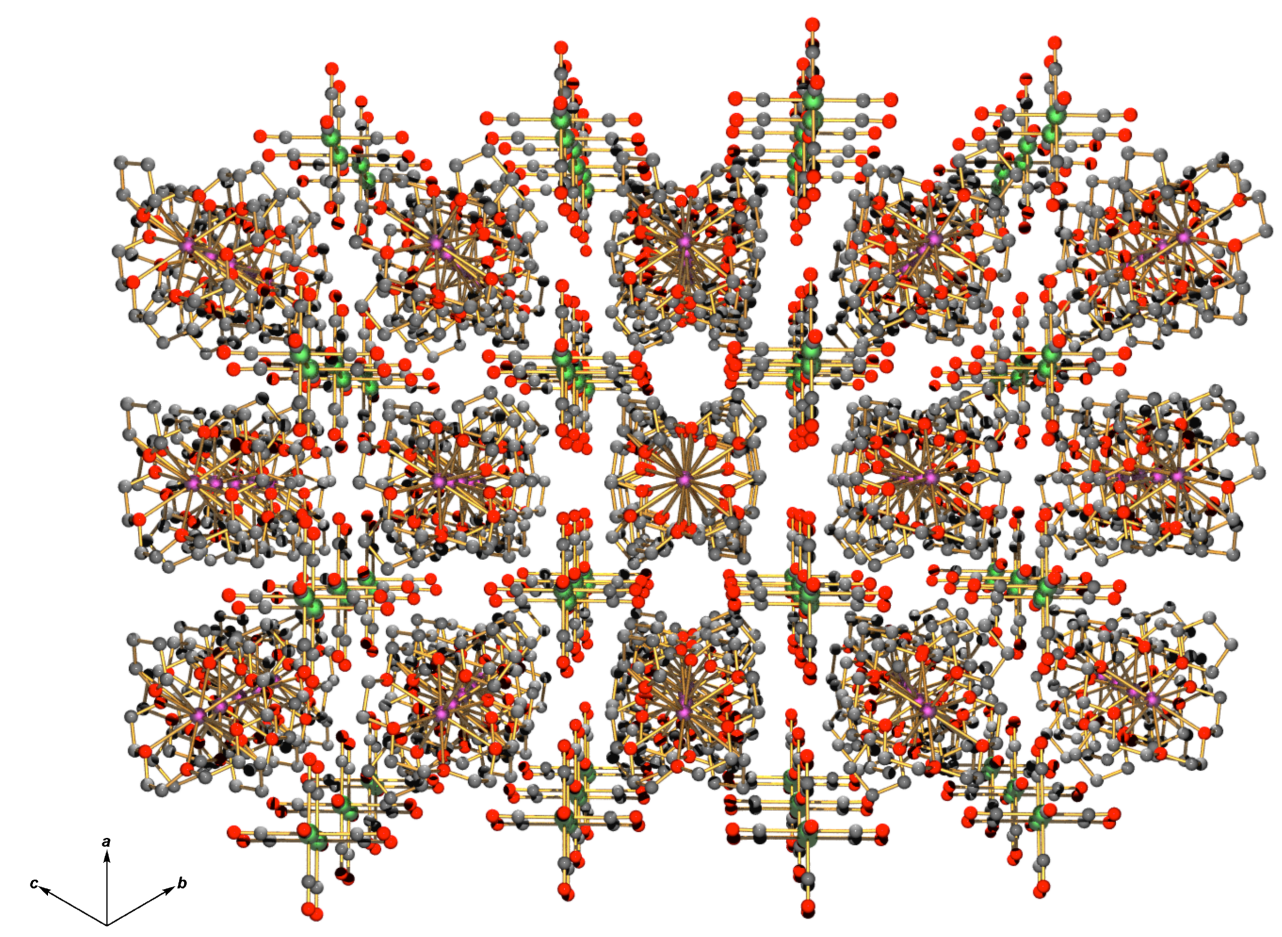

Figure 4. Crystal packing diagram for 1. 


\section{Conclusions}

To conclude, we have developed a straightforward synthesis of 1, which contains the free ditungsten decacarbonyl dianion, completing the triad of structurally authenticated group 6 binary homobimetallic metal-carbonyls first established over half a century ago. Surprisingly, in 1 the $\left[(\mathrm{OC})_{5} \mathrm{~W}-\mathrm{W}(\mathrm{CO})_{5}\right]^{2-}$ dianion adopts a $D_{4 \mathrm{~h}}$ (eclipsed) geometry in the solid-state and not the anticipated $D_{4 \mathrm{~d}}$ (staggered) isomer; quantum chemical calculations at several levels of theory all point to the latter geometry being intrinsically favoured in the gas-phase, with the $D_{4 \mathrm{~h}}$ structure being a rotational transition state linking $D_{4 \mathrm{~d}}$ minima. It is therefore concluded that the gas-phase transition state becomes a minimum on the potential energy surface when subjected to crystal packing in the solid-state.

\section{Experimental}

\section{Preparation of $\left[(\mathrm{OC})_{5} \mathrm{~W}-\mathrm{W}(\mathrm{CO})_{5}\right]\left[\mathrm{K}(18-\text { crown-6)(THF) })_{2}\right]_{2}(1)$}

THF $(20 \mathrm{ml})$ was added to a mixture of $\left[\mathrm{W}(\mathrm{CO})_{6}\right](0.704 \mathrm{~g}, 2.0$ $\mathrm{mmol}$ ) and 18 -crown-6 $(0.53 \mathrm{~g}, 2.0 \mathrm{mmol})$. THF $(20 \mathrm{ml})$ was then added to a separate mixture of potassium metal $(0.08 \mathrm{~g}$, $2.0 \mathrm{mmol}$ ) and naphthalene $(0.26 \mathrm{~g}, 2.0 \mathrm{mmol})$, and the mixture agitated until all the potassium was consumed. The completed potassium naphthalenide solution was added dropwise to the $\mathrm{W}(\mathrm{CO})_{6}$ solution, instantaneously forming a red solution which was allowed to stir over 3 days, resulting in a brown solution. Volatiles were removed in vacuo and the resulting brown solid was washed with pentane $(2 \times 10 \mathrm{ml})$, then extracted into THF $(5 \mathrm{ml})$ and filtered away from the remaining solid. Volatiles were removed in vacuo to afford 1 as a yellow powder. Crystals of 1 suitable for X-ray diffraction were grown from a concentrated THF solution at ambient temperature. Yield: $0.728 \mathrm{~g}, 58 \%$. Extended drying under vacuum removes the THF as evidenced by the elemental analyses. Anal. Calc'd for $\mathrm{C}_{34} \mathrm{H}_{48} \mathrm{~K}_{2} \mathrm{O}_{22} \mathrm{~W}_{2}$ : C 32.55; $\mathrm{H} 3.86 \%$. Found: C 32.80; H 3.90\%. ${ }^{1} \mathrm{H}$ NMR (500 MHz, $\mathrm{d}_{8}$-THF) $\delta: 3.64$ $\left(48 \mathrm{H}, \mathrm{s}, \mathrm{CH}_{2}\right), 3.62\left(16 \mathrm{H}, \mathrm{m}, \operatorname{THF}\left(\mathrm{O}-\mathrm{CH}_{2}\right)\right), 1.78(16 \mathrm{H}, \mathrm{m}$, $\left.\operatorname{THF}\left(\mathrm{CH}_{2}-\mathrm{CH}_{2}\right)\right) .{ }^{13} \mathrm{C}\left\{{ }^{1} \mathrm{H}\right\}$ NMR (d $\mathrm{d}_{8}$-THF) $\delta: 222.86$ (s, W-CO) 70.21 (s, O-CH $\mathrm{CH}_{2}, 66.63\left(\mathrm{THF}\left(\mathrm{O}-\mathrm{CH}_{2}\right)\right), 23.33\left(\mathrm{THF}\left(\mathrm{CH}_{2}-\mathrm{CH}_{2}\right)\right)$. FTIR $\mathrm{v} / \mathrm{cm}^{-1}$ (ATR): $2905(\mathrm{w}), 1938(\mathrm{~m}), 1863(\mathrm{~s}), 1772(\mathrm{~s}), 1467(\mathrm{w})$, $1351(\mathrm{w}), 1095$ (s), 959 (s), $833(\mathrm{~m}), 576(\mathrm{~s})$. Raman v/cm ${ }^{-1}$ (Neat, s15 mW): 2019 (w), 1960 (br), 1904 (m), 1794 (w), 595 (w), 447 (s), 405 (m), 97 (vs).

\section{Acknowledgements}

We are grateful to the UK Engineering and Physical Sciences Research Council (grants EP/M027015/1, and EP/P001386/1), European Research Council (grant CoG612724), Royal Society (grants UF110005 and RG110238), The University of Manchester, and The University of Manchester Computational Shared Facility for computational resources and associated support services.

\section{Notes and references}

¥ CCDC 1953958 (1) contains the supplementary crystallographic data for this paper. These data can be obtained free of charge from The Cambridge Crystallographic Data Centre. All other data are available from the corresponding authors on request.

1 a) W. Heijser, E. Jan Baerends and P. Ros, Faraday Symp., Chem. Soc. 1980, 14, 211; b) E. W. Abel and F. G. A. Stone, $Q$. Rev. Chem. Soc., 1969, 23, 325.

2 a) Molecular Metal-Metal Bonds: Compounds, Synthesis, Properties, Ed S. T. Liddle, Wiley VCH, Weinheim, Germany, 2015; b) Multiple Bonds Between Metal Atoms, $3^{\text {rd }}$ Edition, Eds F. A. Cotton, C. A. Murillo, R. A. Walton, Springer-Verlag, New York, 2005.

3 a) T. Y. Garcia, J. C. Fettinger, M. M. Olmstead and A. L. Balch, Chem. Commun., 2009, 7143; b) L. -Y. Hsu, N. Bhattacharyya and S. G. Shore, Organometallics, 1985, 4, 1483; c) H. B. Chin, M. B. Smith, R. D. Wilson and R. Bau, J. Am. Chem. Soc., 1974, 96, 5285; d) L. B. Handy, J. K. Ruff and L. F. Dahl, J. Am. Chem. Soc., 1970, 92, 7312; e) M. F. Bailey and L. F. Dahl, Inorg. Chem., 1965, 4, 1140; f) L. F. Dahl, E. Ishishi and R. E. Rundle, J. Chem. Phys., 1957, 26, 1750.

4 H. Borrmann, A. M. Pirani and G. J. Schrobilgen, Acta Cryst., 1997, C53, 1007.

5 P. Vilarrubias, Mol. Phys. 2016, 114, 1794.

6 D. M. Adams, P. D. Hatton, A. C. Shaw and T. -K. Tan, J. Chem. Soc. Chem. Comm., 1981, 226.

7 H. Behrens and J. Vogl, Chem. Ber., 1963, 96, 2220.

8 G. B. Deacon, Z. Guo, P. C. Junk and J. Wang, Angew. Chem. Int. Ed., 2017, 56, 8486.

9 I. P. Beletskaya, A. Z. Voskoboynikov, E. B. Chuklanova, A. I. Gusev and A. V. Kisin, J. Organomet. Chem., 1993, 454, 1.

10 a) E. Lu, A. J. Wooles, M. Gregson, P. J. Cobb and S. T. Liddle, Angew. Chem. Int. Ed., 2018, 57, 6587; b) A. J. Ayres, M. Zegke, J. P. A. Ostrowski, F. Tuna, E. J. L. McInnes, A. J. Wooles and S. T. Liddle, Chem. Commun., 2018, 54, 13515; c) T. M. Rookes, E. P. Wildman, G. Balázs, B. M. Gardner, A. J. Wooles, M. Gregson, F. Tuna, M. Scheer and S. T. Liddle, Angew. Chem. Int. Ed., 2018, 57, 1332; d) D. Patel, F. Moro, J. McMaster, W. Lewis, A. J. Blake and S. T. Liddle, Angew. Chem. Int. Ed., 2011, 50, 10388; e) B. M. Gardner, D. Patel, A. D. Cornish, J. McMaster, W. Lewis, A. J. Blake and S. T. Liddle, Chem. Eur. J., 2011, 17, 11266; f) B. Vlaisavljevich, P. Miró, C. J. Cramer, L. Gagliardi, I. Infante and S. T. Liddle, Chem. Eur. J., 2011, 17, 8424; g) B. M. Gardner, J. McMaster, F. Moro, W. Lewis, A. J. Blake and S. T. Liddle, Chem. Eur. J., 2011, 17, 6909; h) D. Patel, D. M. King, B. M. Gardner, J. McMaster, W. Lewis, A. J. Blake and S. T. Liddle, Chem. Commun., 2011, 47, 295 ; i) B. M. Gardner, J. McMaster, W. Lewis and S. T. Liddle, Chem. Commun., 2009, 2851; j) S. T. Liddle, J. McMaster, D. P. Mills, A. J. Blake, C. Jones and W. D. Woodul, Angew. Chem. Int. Ed., 2009, 48, 1077.

11 See the Electronic Supplementary Information for full details. 12 P. Pyykkö, J. Phys. Chem. A 2015, 119, 2326.

13 A. L. Rheingold and J. R. Harper, Acta Cryst., 1991, C47, 184.

14 G. O. Evans, W. T. Wozniak and R. K. Sheline, Inorg. Chem., 1970, 9, 979.

15 A. P. Sattelberger, K. W. McLaughlin and J. C. Huffman, J. Am. Chem. Soc., 1981, 103, 2880.

16 M. Ciftci, M. A. Tasdelen and Y. Yagci, Polym. Chem., 2014, 5, 600.

17 H. Borrmann, A. M. Piriani and G. J. Schrobilgen, Acta Cryst., 1997, C53, 19. 


\section{ToC Entry}

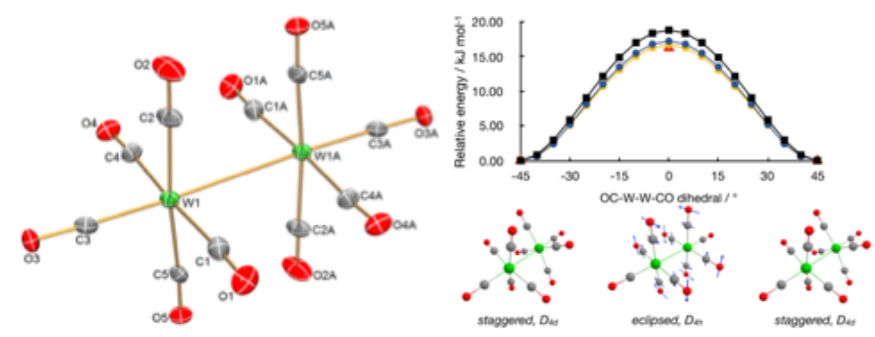

The $D_{4 \mathrm{~h}}$ isomer of $\left[(\mathrm{OC})_{5} \mathrm{~W}-\mathrm{W}(\mathrm{CO})_{5}\right]^{2-}$ is a transition state in the gas-phase but isolated in the solid-state. 